\section{TEACHING MODULATED STRUCTURES - A PROJECT-BASED} APPROACH

T. Wagner ${ }^{1}$ S. Schmid ${ }^{2}$ V. Petricek ${ }^{3}$

Sophienstr. 99 KARLSRUHE D-76135 GERMANY

${ }^{1}$ Bruker AXS, Oestliche Rheinbrueckenstr. 50, 76187 Karlsruhe, Germany ${ }^{2}$ Institut fuer Anorganische Chemie, Eberhard-Karls-Universitaet Tuebingen, Auf der Morgenstelle 18, 72076 Tuebingen, Germany ${ }^{3}$ Institute of Physics, Academy of Sciences of the Czech Republic, 18221 Prague 8, Na Slovance 2, Czech Republic

The importance attributed to modulated structures in recent years is reflected by a rapidly increasing number of publications. Modulated structures can be considered as crystals of a basic structure with a periodic distortion. The distortion can be either displacive (variable atomic positions) and/or occupational (variable composition) in nature.

In either case this variability reveals itself by the existence of so-called satellite reflections, often weaker than the main reflections of the underlying basic structure. The introduction of area detectors has enabled structural scientists to recognize these characteristic diffraction patterns more easily and with JANA2000 a software tool is available that allows to handle the resulting intensity data according to the specific requirements of superspace refinement. $\mathrm{KNbOB}_{2} \mathrm{O}_{5}$, a recent problem from our Application Lab, provides an excellent example for an understandable modulated structure, which, at the same time, fully demonstrates how to proceed with indexing, data processing, structure solution, and refinement.

The underlying concepts of the superspace approach will be presented and discussed step by step via our sample structure. We believe that this type of project-based learning is a valuable addition to the traditional textbook method and will gain more significance in the future as the subjects of crystallographic teaching become more and more complex.

\section{Keywords: TEACHING METHODS MODULATED STRUCTURES SUPERSTRUCTURE}

\section{Acta Cryst. (2002). A58 (Supplement), C187 \\ INVESTIGATION OF MAGNETISM IN PrMn ${ }_{2-\mathrm{x}} \mathrm{T}_{\mathrm{x}} \mathrm{Ge}_{2}(\mathrm{~T}=\mathrm{Fe}$ and $\mathrm{Co})$ BY NEUTRON DIFFRACTION}

$\underline{\text { I. Dincer }}^{1,2}$ Y. Elerman ${ }^{1}$ A. Elmali ${ }^{1}$ H. Ehrenberg ${ }^{2}$ H. Fuess ${ }^{2}$ G. Andrl' ${ }^{3}$ O. Isnard $^{4}$

${ }^{1}$ Dept. of Engineering Physics, Faculty of Engineering, Ankara University, 06100 Besevler-Ankara, Turkey ${ }^{2}$ Institute For Materials Science Structure Analysis Petersenstr. 23 DARMSTADT 64287 GERMANY ${ }^{3}$ Laboratoire L'eon Brillouin(CEA-CNRS), CEN-Saclay, 91191 Gif-Sur-Yvette, France ${ }^{4}$ Institut of Laue-Langevin, Instrument D1B, BP 156, 38042 Grenoble Cedex 9, France

The magnetic properties of the $\operatorname{PrMn}_{2-\mathrm{x}} \mathrm{T}_{\mathrm{x}} \mathrm{Ge} 2(\mathrm{~T}=\mathrm{Fe}$ and $\mathrm{Co})$ compounds with $\mathrm{ThCr}_{2} \mathrm{Si}_{2}$-type structure(space group I $4 / \mathrm{mmm}$ ) have been reinvestigated by neutron diffraction[1, 2]. A typical $\mathrm{SmMn}_{2} \mathrm{Ge}_{2}$-like behavior isobserved for $\operatorname{PrMn}_{1.4} \mathrm{Fe}_{0.6} \mathrm{Ge}_{2}$. The magnetic structures ofPrMn ${ }_{2-\mathrm{x}} \mathrm{Fe}_{\mathrm{x}} \mathrm{Ge}_{2}(\mathrm{x}=0.4,0.6,0.8$, 1.0) andPrMn $\mathrm{Mn}_{2-\mathrm{x}} \mathrm{Co}_{\mathrm{x}} \mathrm{Ge}_{2}(\mathrm{x}=0.4,0.5,0.8)$ have been determined between 2 and $300 \mathrm{~K}$, and the $\mathrm{x}-\mathrm{T}$ magnetic phase diagramof this system is proposed. It has been shown that the substitution of $\mathrm{Mn}$ by $\mathrm{T}$ drastically reduces thetransition temperatures. Above the Curie temperature for $\operatorname{PrMn}_{2-\mathrm{x}} \mathrm{Fe}_{\mathrm{x}} \mathrm{Ge}_{2}$ with $\mathrm{x}<0.8$ and $\mathrm{PrMn}_{2-\mathrm{x}} \mathrm{Co}_{\mathrm{x}} \mathrm{Ge}_{2}$ with $\mathrm{x}<0.8$ and the Néel temperature for $\operatorname{PrMn}_{2-\mathrm{x}} \mathrm{Fe}_{\mathrm{x}} \mathrm{Ge}_{2}$ with $\mathrm{x}$ $=0.8$ and 1.0, the intralayer antiferromagnetic ordering within (001) Mn layers is observed. At low temperatures, Pr moments does not order for $\mathrm{PrMn}_{2}$ ${ }_{x} \mathrm{Fe}_{\mathrm{x}} \mathrm{Ge}_{2}$ with $\mathrm{x}=0.8$ and 1.0 and $\operatorname{PrMn}_{1.2} \mathrm{Co}_{0.8} \mathrm{Ge}_{2}$. These results are compared with $\mathrm{NdMn}_{2-\mathrm{x}} \mathrm{Fe}_{\mathrm{x}} \mathrm{Ge}_{2}$ [3] and $\mathrm{LaMn}_{2-\mathrm{x}} \mathrm{Fe}_{\mathrm{x}} \mathrm{Si}_{2}$ [4] in respect to the effect of $\mathrm{Fe}$ and Co substitution on the interplane magnetic couplings. The F-AF transition at a critical Mn-Mn interatomic distance $d_{M n-M n}$ within the (001) Mn layers (intralayer) is larger than the value $(2.865 \AA)$ for pure Mn compounds (e.g. $\mathrm{SmMn}_{2} \mathrm{Ge}_{2}$ ). Electronic effects also act on this magnetic behavior, as suggested by the ferromagnetic interlayer exchange observed inUMn $\mathrm{XX}_{2}(\mathrm{X}=\mathrm{Ge}$ or $\mathrm{Si})$ in spite of short Mn-Mn separation $\left(\mathrm{d}_{\mathrm{Mn}-\mathrm{Mn}}<2.847 \AA\right.$ ).

References

[1] S. Kervan, Y. Elerman, A. Elmali, R. Theissmann, J. Alloys Comp. 327 (2001) 27.[2] I. Dincer, Y. Elerman, A. Elmali, H. Ehrenberg, H. Fuess, J. Alloys Comp. 334 (2002) 72.

[3] G. Venturini, B. Malaman, E. Ressouche, J. Alloys Comp. 237 (1996) 61

[4] I. Dincer, Y. Elerman, A. Elmali, H. Ehrenberg, H. Fuess, in preparation.

Keywords: RARE-EARTH MANGANESE GERMANIDES, MAGNETIC X-T PHASE DIAGRAM, NEUTRON DIFFRACTION
Acta Cryst. (2002). A58 (Supplement), C187

DESIGN OF MODULAR CRYSTALLOGRAPHIC LECTURES WITH XML BASED TECHNOLOGIES

G. Schuck W. Steurer

ETH Zurich Laboratorium fur Kristallographie Sonneggstr. 5 ZURICH CH8092 SWITZERLAND

Web-based courses in crystallography have become quite common. Since these applications are mostly HTML- or PDF based, we find often that content, structure and presentation are lumped together. HTML- or PDF presentations can be produced with standard scientific programs like Latex or Microsoft Word but sharing, reuse and modification of these data is impeded. That means HTML- and PDF based courses are somewhat inflexible and also devicedependent. Most of the web-based crystallographic courses have an auditorium with a very different educational background. Crystallographic lectures may be of interest for earth scientists, materials scientists, chemists, physicists or biologists. Consequently, we need different lectures for each target group and a high degree of flexibility and modularity in the teaching environment. In order to achieve such a flexibility, course modules may be prepared in the Extensible Markup Language (XML) [1], maintained in a repository and organized way using metadata based on standards like ARIADNE [2]. Markup descriptions are usually device-independent. The device-dependent information is stored in a separate description, called style sheet. The word 'style' refers to the mapping between the markup tags and the semantics. There are several proposed standards for describing style information like XSL (Extensible Style sheet Language) [3]. The materials required for a course are generated as per the request in the desired formats (HTML for internet-based learning material, PDF for printed manuscripts, PPT for slide presentations) by the content repository using XSL processing techniques. For further details and discussion, please visit the project website [4].

References

[1] http://www.w3.org/XML/

[2] http://www.ariadne-eu.org/

[3] http://www.w3.org/Style/XSL/

[4] http://www.kristall.ethz.ch/LFK/teach2/XML

Keywords: XML DEVICE INDEPENDENT MODULAR LECTURES

Acta Cryst. (2002). A58 (Supplement), C187

STRUCTURAL FEATURES OF 2-S SUBSTITUTED TETRAHYDROPYRAN O,S,S-ACETALS

J. Kansikas $^{1}$ K. Sipila

University of Helsinki Department of Chemistry PO Box 55 HELSINKI 00014 FINLAND

${ }^{1}$ University of Helsinki, Department of Chemistry, Laboratory of Inorganic Chemistry ${ }^{2}$ University of Helsinki, Department of Chemistry, Laboratory of Organic Chemistry

We have studied the syntheses and structures of novel O,S,S-acetal compounds where the $\mathrm{O}$ atom belongs to the tetrahydropyran (THP) ring with the $\mathrm{S}$ sidechain at 2-position and the other $\mathrm{S}$ atom of the dithioacetal moiety is substituted by an aryl group.[1-6] Alkylations of these lithiated O,S,S-acetals showed remarkable diastereoselectivity, which was rationalized by the locked conformation of the five-membered ring caused by lithium-to-oxygen coordination.[5] 2-(Phenanthren-9-ylthiomethylthio)tetrahydropyran (1) is the only crystalline starting material for the lithiations obtained so far. Compound 1 crystallizes in space group $P 2_{1} / c$. The data were collected at $193 \mathrm{~K}$. The Ssidechain at the THP ring is axial with the C-O-C-S torsion angle of $66.8(2)^{\circ}$. The C-S-C-S torsion angle at the phenanthrene side is $176.7(1)^{\circ}$ and at the THP side 78.3(1) deg. The $\mathrm{S}$ atom distance from the aromatic $\mathrm{C}$ atom is 1.765(2) $\AA$ and 1.810(2) $\AA$ from the central $\mathrm{C}$ atom. The other $\mathrm{S}$ atom distance from the $\mathrm{C}$ atom of the THP ring is 1.845(2) $\AA$ and 1.797(2) $\AA \mathrm{A}$ from the central $\mathrm{C}$ atom.

References

[1] Kansikas, J., Leskelä, M., Sipilä, K. \& Hase, T. (1995) Acta Chem. Scand. 49, 809-812.

[2] Kansikas J., Sipilä, K. \& Hase, T. (1996) Acta Chem. Scand. 50, 11471152 .

[3] Kansikas J. \& Sipilä K. (2000) Acta Crystallogr. C56, 1383-1385.

[4] Kansikas, J. \& Sipilä, K. (2001) Acta Crystallogr. E57, 335-337.

[5] Sipilä, K., Hase, T., Koskimies, J., Matikainen, J. \& Kansikas J., Phosphorus, Sulfur and Silicon, In press.

[6] Sipilä, K. \& Kansikas J., Phosphorus, Sulfur and Silicon, In press.

Keywords: LOW TEMPERATURE O,S,S-ACETAL 2-STETRAHYDROPYRAN 